\title{
Assessment of Road Safety Audit of NH-69, Karnataka State, India
}

\author{
Jayaprakash M C, Shreyas K S, Vikram M C, Manasa Nair
}

\begin{abstract}
Road Safety Audit (RSA) is a formal procedure for assessing accident potential and safety performance of new and existing roads. RSA is an efficient, cost effective and proactive approach to improve safety of the road users with leading to any trend of accidents and their impacts. RSA appears to be an ideal tool for improving road safety in India, as basic and accurate data on accidents have yet to be collected in a scientific way as well as in a systematic method. It is evident from the traffic composition for the countries like India, where heterogeneous traffic with varying vehicle types differing in their vehicle static and dynamic characteristics.

The project stretch considered is NH-69 (Bhadhravathi to Shivamogga - Karnataka State) ranging $22.1 \mathrm{Kms}$. The present study deals with road inventory, signage inventory, traffic volume count survey, spot speed study, Speed and delay study and other surveys such as topographic survey and Accident data has been collected for the stretch for a period of 2012-16 is collected and analysis is carried out. The study aims to evaluate Road Safety Audit of a section of four-lane National Highway (NH)-69 and will focus on evaluating the benefits of the proposed actions that have emanated from deficiencies identified through the audit process. Missing road and median markings to be done and speed signs should match with speed. Access and service lanes are also deficient which requires immediate improvement.
\end{abstract}

Keywords (Index Terms):- Road Safety Audit (RSA), NH-69, road safety in India and speed signs.

\section{INTRODUCTION}

In 1980's the Road Safety Audit (RSA) process was started in the United Kingdom. On 11 May 2011, the plan of action for Road Safety 2011-2020 was launched around 100 countries including India. The main goal of the plan is to prevent five million road traffic deaths globally by 2020 (Arun S Bagi et al.). Road safety audit has the greatest ability when it is considered for traffic design before and after the construction stage. Main purpose of RSA is to focus on the accident influential and safety condition of the highways. RSA is a formal procedure having definite aim with standard procedure. For the effective outcome, its need to be conducted by appropriate experienced and trained persons and they should be of independent of design team. An audit procedure initiates from beginning of design and at construction stage.RSA can also conducted on the existing road, so it can help to identify the deficiencies and formopportunity becomes to identify the highway engineering measures to improve safety.

The start of this century, the rate generation of mechanized vehicle has been expanding constantly. The awesome incrementinnumberofenginevehiclesoutandabouthasnot similarly coordinating with relating increment in complete length of highway arrange (S. S. Jain et al.,). The highway length has not possessed the capacity to take care of the demand made by the gigantic development of vehicle populace. The blended movement condition winning on our street organize has additionally exasperated the activity circumstance. Along these lines the vehicles populace increments in step by step (Atul Kumar). Because of this advancement with changing condition situation, the rates of mishaps are expanding radically. RSA is the principle worry tolessenmischance.MischancefatalitiesrateinIndiaishigh inthecorrelationwiththatinthecreatednations.

Fundamental methodologies of road safety are counteractive action and diminishment of accidents. In accident decrease, consciousness of accidents that happened on existing highway to enhance the outline of highway or to impact the conduct of road user is utilized (S. S. Jain et al.,).

In accident prevention, learning of aptitude in safe street outline - street geometry, and in addition the materials utilized. Accident reducing action ought to be the fundamentaltargetofthehighwayspecialisttoguaranteethat theroadsaresafe(PavanDeshpande). Atthepointwhenthe accident rate is least on roadway extend then the highway is to be considered as more secure for road user. In the event that accident rate is more than the street is not protected, paying little respect whether all principles were seen amid arranging andplan

\section{A. Road Accident Scenario inIndia}

The Road safety is more important in India because close to $5,00,000$ road accidents and nearly $1,46,000$ deaths caused in 2015.Non highway roads witnessed $47.6 \%$ of total accidents. This is followed by NH with a rate of $28.4 \%$ and SH with $24 \%$. The $2 \%$ length on National Highway carry $40 \%$ ofgoodtraffic, while $7 \%$ ofStateHighwaycarry $30 \%$ of good traffic. The road safety on Indian roads has slowly worsened over the past years. As seen from the below table andgraph,numberofdeathsisincreasedyearbyyear(PavanDesh pande).

\section{B. Projectlocation}

NH-69 is a major National Highway in India that runs alongthestatesof Andhra Pradesh and Karnataka. The western terminal is at the junctionofNH66nearHonnavaraandterminatesattheeast end at Chittoor. It passes through Honnavar, Sagara, Shivamogga, Banavara, Sira, Madhugiri, Chinthamani, and Mulabagilu in Karnataka and in Andhra Pradesh it passes throughPalamaner,Chittoor.NH-69is625kminlength. 


\section{StudyArea}

A portion of NH-69 was selected for project.The selected stretchhasabypassportionofBhadravathi.Thestretchstarts fromKm183.100(atjoiningofbypassandNH-69)andends at $\mathrm{Km} 205.2$ (at MRS circle). The length of study section is approximately $22.1 \mathrm{Kms}$.

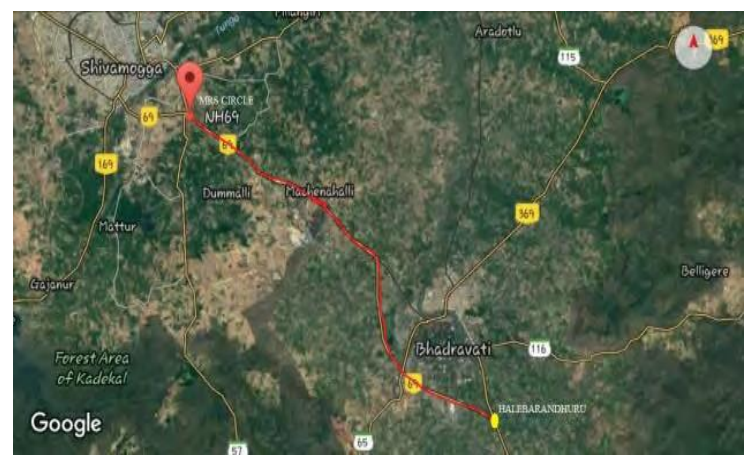

Fig. 1:Spatial view of study area

\section{OBJECTIVES}

- To examine safety features and find out deficiencies and conflict point in the road network which lead to accident and safety hazards to roadusers.

- ToconductaRSAaccordingtospecificationgiveninthe IRC:SP:88:2010

\section{METHODOLOGY}

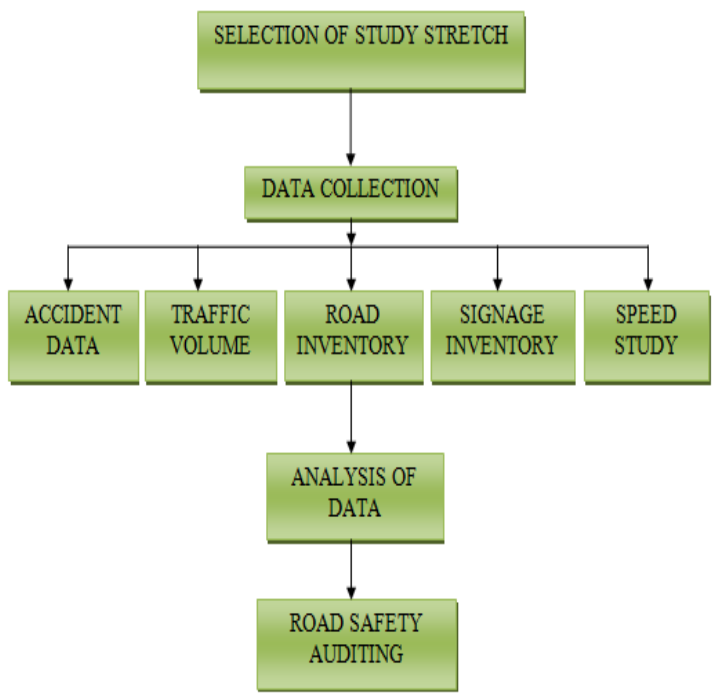

Fig. 2: Flow chart of methodology

\section{RESULTS ANDDISCUSSIONS}

ThemainaimoftheRSAistoensuretheentirenewroadand existing road network operate safely. Road safety audits evaluatetheoperationofaroadbyfocusingonroadsafetyas pedestrians, cyclists, motorcyclists, truck/bus drivers, onroadpublictransportusers, etc.Soforthatdifferentdata's are collected like accident data, traffic data and road inventorydata.

\section{A. Accidentstatistics}

The road accident data was collected from Tunganagara Police Station, Vidyanagara Police Station, and Bhadravathi TrafficPoliceStationlimitsoffiveyearsdatafrom2012-16.
Accident data from Bhadravathi Police Station (ch.183.100-ch.192.500)

Table 1: Year Wise Road Accident Statistics of Selected Stretch

\begin{tabular}{|c|c|c|c|}
\hline Year & $\begin{array}{c}\text { No of } \\
\text { accidents }\end{array}$ & $\begin{array}{c}\text { Total no. } \\
\text { of deaths }\end{array}$ & $\begin{array}{c}\text { Total no. } \\
\text { of injuries }\end{array}$ \\
\hline 2012 & 43 & 4 & 51 \\
\hline 2013 & 41 & 7 & 57 \\
\hline 2014 & 51 & 15 & 50 \\
\hline 2015 & 28 & 6 & 28 \\
\hline 2016 & 35 & 9 & 32 \\
\hline
\end{tabular}

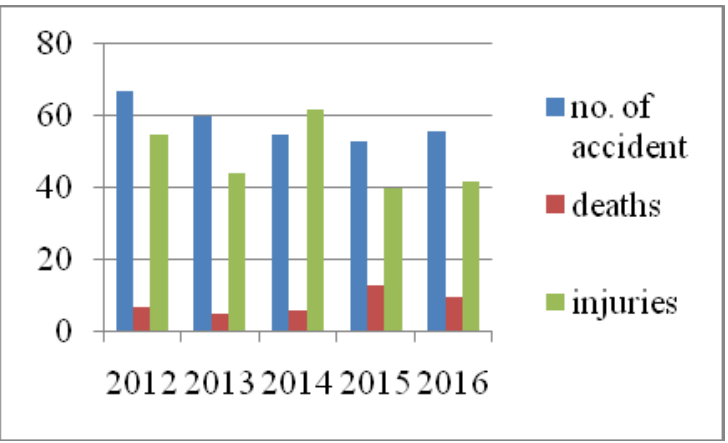

Fig. 3: Accident Statistics of Selected Stretch (ch.183.100 - ch.192.500)

Accident data from Vidyanagara and Tunganagara Police Station (ch. 192.500-ch.205.200)

Table 2: Year Wise Road Accident Statistics of Selected Stretch

\begin{tabular}{|c|c|c|c|}
\hline Year & $\begin{array}{c}\text { No. of } \\
\text { accidents }\end{array}$ & $\begin{array}{c}\text { Total no. } \\
\text { of deaths }\end{array}$ & $\begin{array}{c}\text { Total no. of } \\
\text { injuries }\end{array}$ \\
\hline 2012 & 67 & 7 & 55 \\
\hline 2013 & 60 & 5 & 44 \\
\hline 2014 & 55 & 6 & 60 \\
\hline 2015 & 53 & 13 & 38 \\
\hline 2016 & 56 & 10 & 39 \\
\hline
\end{tabular}

\section{B. Spot SpeedStudy}

Spot speed is the instantaneous speed at a particular section or a point. There are different methods are used. In the first method, the time taken by the vehicle to travel a short distance is determined. Then the instantaneous speed is determined. Then the instantaneous speed is measured by pre calibrated radar equipment which displays or records the speed in desired units such as kmph. In this project, Radar Gun is used.

Results of spot speed study (ch.183.100- ch.192.500)

Modal speed= $49 \mathrm{Kmph}$. 
Design speed $\left(98^{\text {th }}\right.$ percentile $)=\mathbf{8 0 K m p h}$.

Maximum speed $\left(85^{\text {th }}\right.$ percentile $)=70 \mathrm{Kmph}$.

Minimum speed $\left(15^{\text {th }}\right.$ percentile $)=39 \mathrm{Kmph}$.

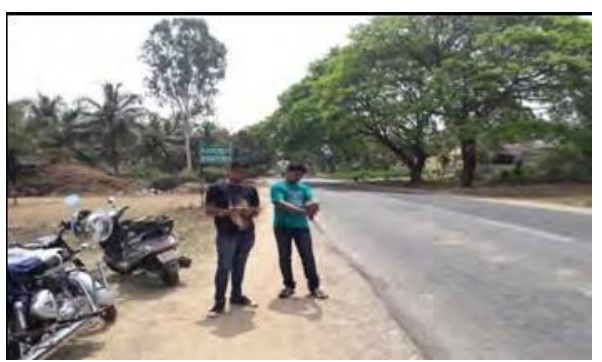

Fig. 4: Spot speed study using RADAR

At section from ch.183.100 - ch.192.500 (undivided 2 lane highway) spot speeds are summarized in table below.

Table 3: Frequency Distribution of Spot Speed Data

\begin{tabular}{|c|c|c|c|c|}
\hline \multicolumn{5}{|c|}{ Frequency distribution of spot speed data } \\
\hline $\begin{array}{c}\text { Speed } \\
\text { range } \\
\text { Kmph }\end{array}$ & $\begin{array}{c}\text { Mean } \\
\text { speed } \\
\text { Kmph }\end{array}$ & Frequency & $\begin{array}{c}\text { Percentage } \\
\text { frequency }\end{array}$ & $\begin{array}{c}\text { Cumulative } \\
\text { frequency }\end{array}$ \\
\hline $0-10$ & 5 & 0 & 0 & 0 \\
\hline 1020 & 15 & 0 & 0 & 0 \\
\hline $20-30$ & 25 & 4 & 3.2 & 3.2 \\
\hline $30-40$ & 35 & 12 & 9.6 & 12.1 \\
\hline $40-50$ & 45 & 28 & 22.4 & 35.2 \\
\hline $50-60$ & 55 & 28 & 22.4 & 57.6 \\
\hline $60-70$ & 65 & 24 & 19.2 & 76.8 \\
\hline $70-80$ & 75 & 21 & 16.8 & 93.6 \\
\hline $80-90$ & 85 & 5 & 4 & 97.6 \\
\hline $90-100$ & 95 & 3 & 2.4 & 100 \\
\hline \multicolumn{6}{|c|}{ Total } & 125 & 100 & \\
\hline \multicolumn{7}{|c|}{} \\
\hline
\end{tabular}

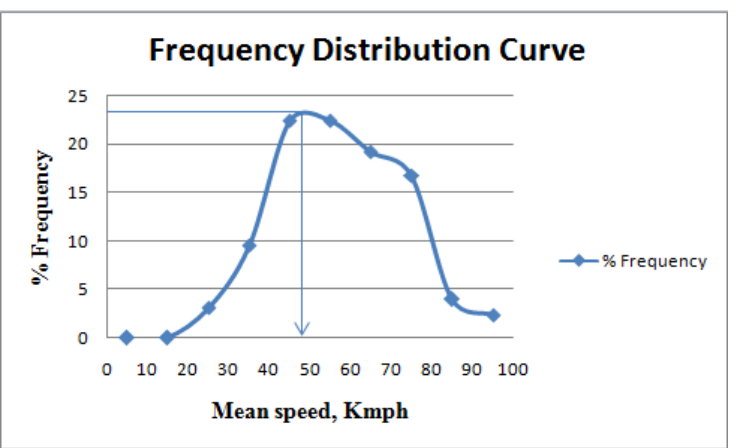

Fig. 5: Frequency Distribution Curve

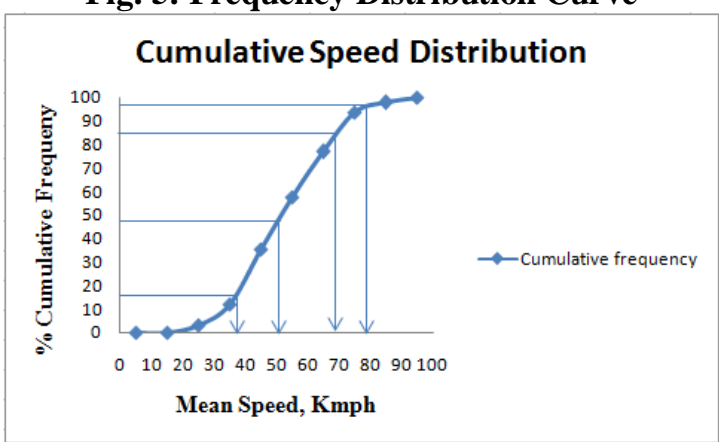

Fig. 6: Cumulative Speed Distribution Curve At section from ch.192.500 - ch.205.200 (divided 4 lane highway) spot speeds are summarized in table below.
Table 4: Frequency Distribution of Spot Speed Data Frequency distribution of spot speed data

\begin{tabular}{|c|c|c|c|c|}
\hline $\begin{array}{l}\text { Speed } \\
\text { range } \\
\text { Kmph }\end{array}$ & $\begin{array}{l}\text { Mean } \\
\text { speed } \\
\text { Kmph }\end{array}$ & $\begin{array}{c}\text { Frequ } \\
\text { ency }\end{array}$ & $\begin{array}{l}\text { Percent } \\
\text { age } \\
\text { frequen }\end{array}$ & $\begin{array}{l}\text { Cumulat } \\
\text { ive } \\
\text { frequenc }\end{array}$ \\
\hline $0-10$ & 5 & 0 & 0 & 0 \\
\hline 1020 & 15 & 0 & 0 & 0 \\
\hline $20-30$ & 25 & 11 & 3.14 & 3.14 \\
\hline $30-40$ & 35 & 69 & 19.7 & 22.84 \\
\hline $40-50$ & 45 & 87 & 24.85 & 47.69 \\
\hline $50-60$ & 55 & 106 & 30.28 & 77.97 \\
\hline $60-70$ & 65 & 61 & 17.42 & 95.39 \\
\hline $70-80$ & 75 & 16 & 4.57 & 100 \\
\hline $80-90$ & 85 & 0 & 0 & 100 \\
\hline $90-100$ & 95 & 0 & 0 & 100 \\
\hline \multicolumn{2}{|c|}{ Total } & 350 & 100 & \\
\hline
\end{tabular}

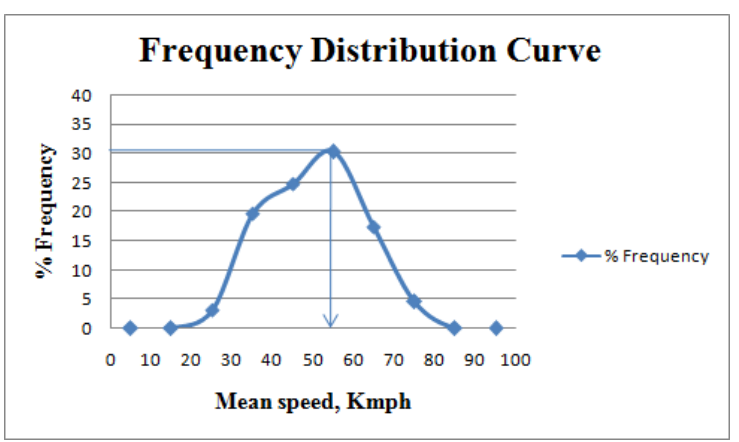

Fig. 7: Frequency Distribution Curve

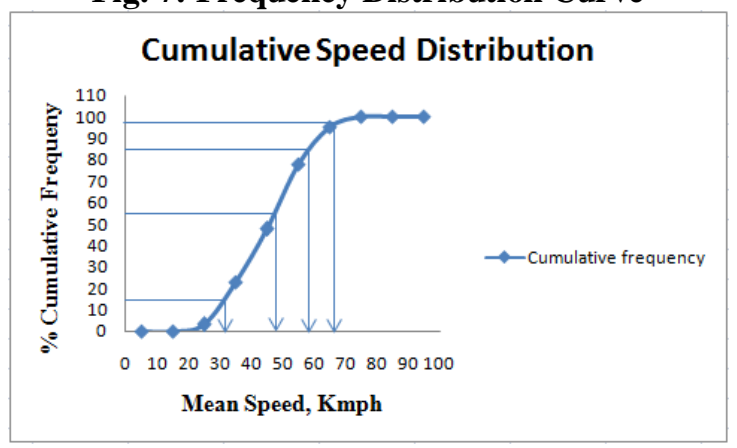

Results of spot speed study (ch.192.500- ch.205.200) Modal speed $=\mathbf{5 5} \mathrm{Kmph}$.

Design speed $\left(98^{\text {th }}\right.$ percentile $)=68 \mathrm{Kmph}$. Maximum speed $\left(85^{\text {th }}\right.$ percentile $)=6 \mathbf{K m p h}$. Minimum speed $\left(15^{\text {th }}\right.$ percentile $)=31 \mathrm{Kmph}$.

\section{Traffic VolumeCount}

A traffic count is a count of vehicular or pedestrian traffic, which is conducted along a stretch.Trafficvolumestudyis

conductedtofindthenumber,movements, andclassification of vehicles at thegiven stretch. In this project, volume count isconductedfor3daysi.e., weekendandoneworkingdayfor 12 hours from 6.00am to6.00pm.

Published By: 
Table 5: Traffic composition (ch.205.200 to ch. 192.500)

\begin{tabular}{|c|c|c|c|c|c|c|c|}
\hline \multirow{3}{*}{\multicolumn{2}{|c|}{ Types of Vehicles }} & \multicolumn{6}{|c|}{ AVERAGE DAILY TRAFFIC } \\
\hline & & \multicolumn{3}{|c|}{ Total Vehicles } & \multicolumn{3}{|c|}{ \% Composition } \\
\hline & & $\stackrel{g}{g}$ & 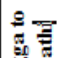 & $\overline{\bar{g}}$ & $\stackrel{g}{g}$ & $\stackrel{8}{\exists}$ & 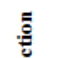 \\
\hline \multirow{10}{*}{ 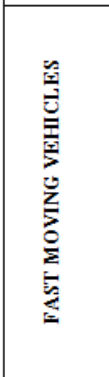 } & 2-Wheeler & 4364 & 3624 & 7988 & 56.11 & 54.42 & 55.33 \\
\hline & 3-Wheeler & 180 & 164 & 344 & 2.31 & 2.46 & 2.38 \\
\hline & Car & 1740 & 1748 & 3488 & 22.37 & 26.25 & 24.16 \\
\hline & LCV/Tempo & 392 & 275 & 667 & 5.04 & 4.13 & 4.62 \\
\hline & Mini-Bus & 97 & 103 & 200 & 1.25 & 1.55 & 1.39 \\
\hline & Standard Bus & 415 & 310 & 725 & 5.34 & 4.66 & 5.02 \\
\hline & 2-Axle & 318 & 223 & 541 & 4.09 & 3.35 & 3.75 \\
\hline & 3-Axle & 115 & 89 & 204 & 1.48 & 1.34 & 1.41 \\
\hline & Multi Axle & 56 & 42 & 98 & 0.72 & 0.63 & 0.68 \\
\hline & Tractor & 51 & 33 & 84 & 0.66 & 0.50 & 0.58 \\
\hline \multirow{4}{*}{ 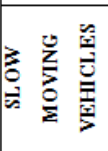 } & Cycle & 20 & 18 & 38 & 0.26 & 0.27 & 0.26 \\
\hline & Hand-Cart & 8 & 10 & 18 & 0.10 & 0.15 & 0.12 \\
\hline & Animal Drawn & 10 & 8 & 18 & 0.13 & 0.12 & 0.12 \\
\hline & Other (Specify) & 11 & 12 & 23 & 0.14 & 0.18 & 0.16 \\
\hline \multicolumn{2}{|c|}{$\frac{1}{\text { Total Vehicles }}$} & 7777 & 6659 & 14436 & 100 & 100 & 100 \\
\hline
\end{tabular}
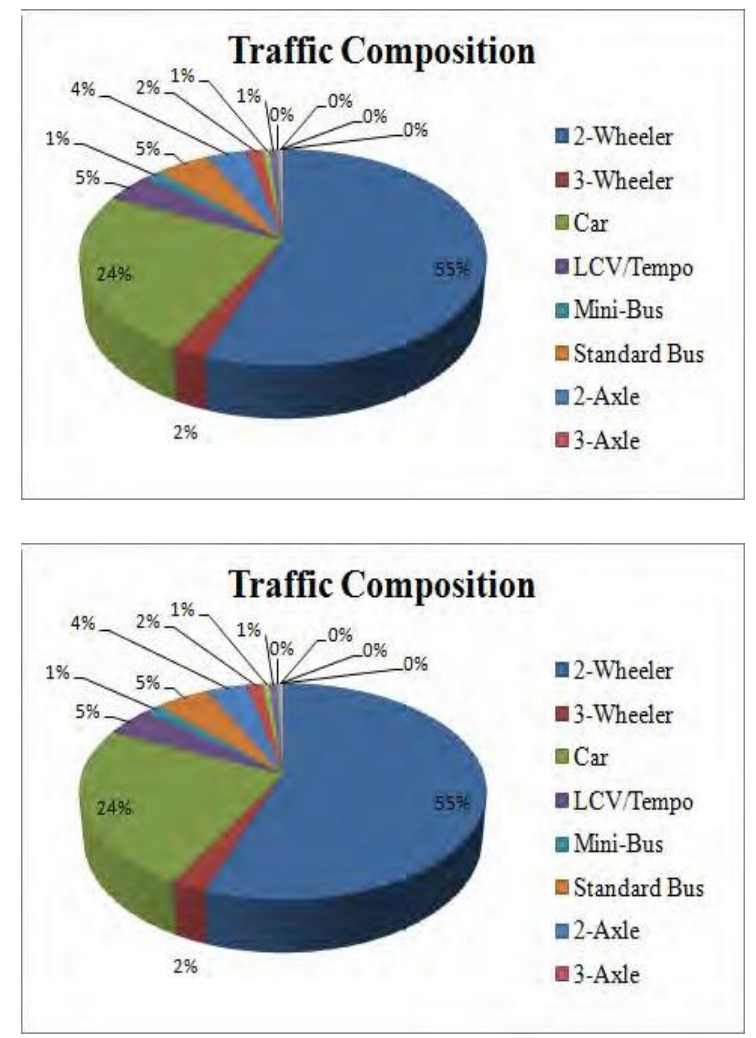

Fig. 9: Traffic Composition

Inthisstretchi.e.,fromch.205.200toch.192.500whichis4 lanehighwaysobservedlargeproportionoftwowheelersand cars. Vehicles like bicycles, tractors and animal drawn are very less in the entire study stretch. And also heavyvehicles like trucks are in considerableproportion.

\section{RoadInventory}

Road inventory survey was conducted in the selected stretch to know the existing conditions like the roadway width and footpath width, shoulder width, type of pavement, condition of pavement, shoulder, footpath, and details of cross road. Cross section includes width of carriageway, width of shoulders, median, drains etc. Road inventory survey is conducted to know the existing condition of the highway. In RSA, cross section are checked regarding their dimensions are accordance with IRC standards and their performances.

\section{E. Traffic SignageInventory}

Road signs are basically of three types namely, mandatory,

cautionary,informatorysigns. Thereforetrafficsignage inventory is necessary to know present condition of traffic signs in the selected stretch

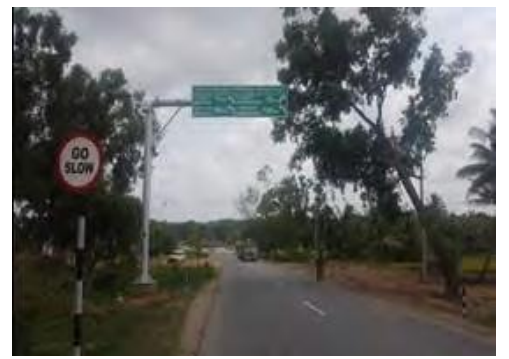

Fig. 10: Road inventory at $194.300 \mathrm{Km}$

\section{F. Black spots on NationalHighway}

Road accident black spot is a stretch of national highway of about $500 \mathrm{~m}$ in length in which either 5 road accidents took placeduringlast3yearsor 10fatalitiestookplaceduringlast 3years. WiththehelpofFIRcopiesaround8blackspotsare identified.

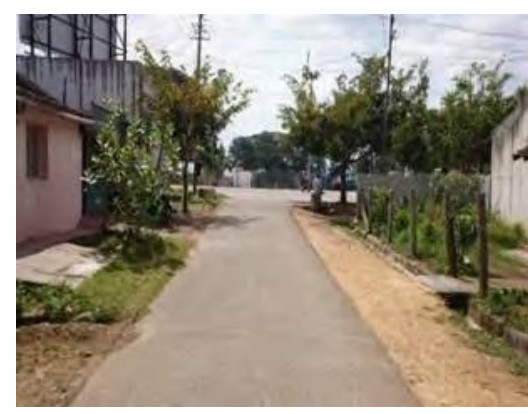

Fig. 11: Lack of sight distance

\section{F. Road SafetyAuditing}

Checklist 8- Alignment

Checklist 9- Cross Section

Checklist 10- Junctions

Checklist 11- Road Signs

Checklist 12- Road Markings

Checklist 13- Lighting

\section{Checklist 14- Roadside Hazards}

Checklist 15- Roadside Facilities

IRC: SP:88-2010provided the checklist for auditing. These checklists help toguide the road safety audit team. These checklists depict the performance and condition that affects the road network in safety point ofview. 
IRC:SP:88-2010has provided 18 checklists for auditing.Fortheexisting highway and for this project checklist are listed as below.

From the road inventory survey, width of shoulder at the selected stretch is not as per IRC standards. The width is varyingfrom $0.3 \mathrm{mto} 3.0 \mathrm{~m}$. Duetothepoormaintenanceof shoulder vegetation covers the width of shoulder (earthen shoulder) and the strength of shoulder is poor. The fig. 15 and fig.16 showing poorly maintained shoulder of inadequate width and strength. During rainy season condition of shoulders would worsen, results in the drainage problem and condition of the pavement may effected.
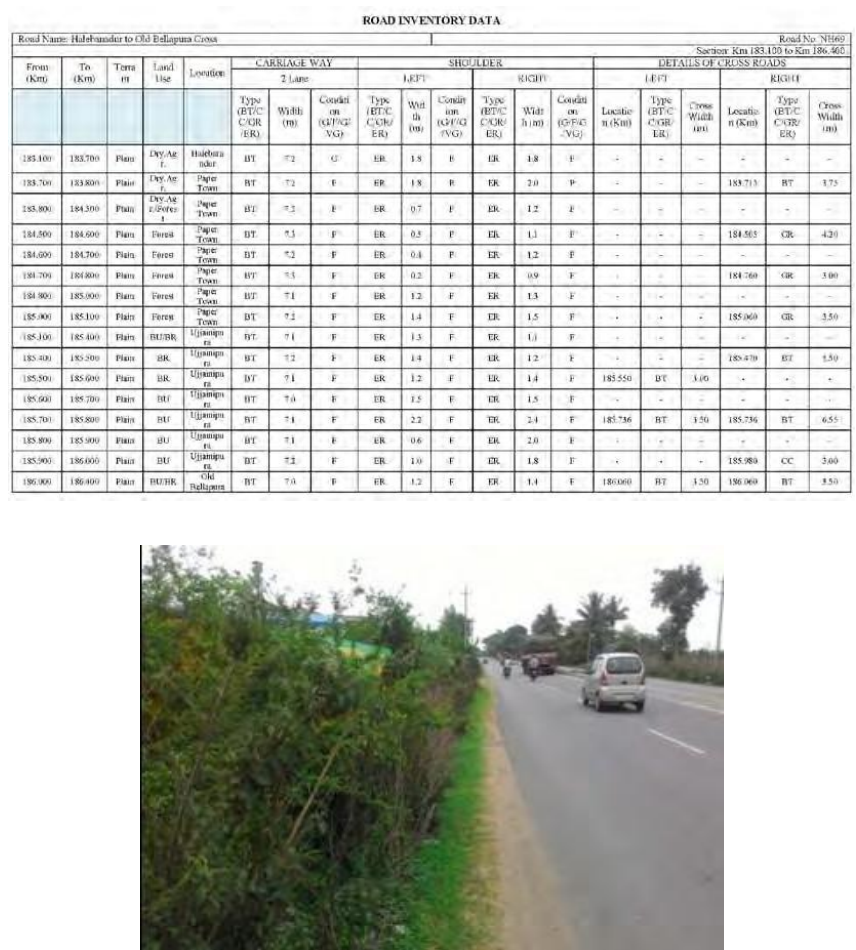

Fig. 12: Inadequate width of shoulder

\section{G. Median}

In selected stretch more number of $\mathrm{T}$ - Junction are present.

Mostofthesejunctionhavepoorsightdistancefortheminor roads due to the presence of vegetations, buildings etc. and alsosignboardsarenotinstalled;speedbreakersarenotused in minorroads.

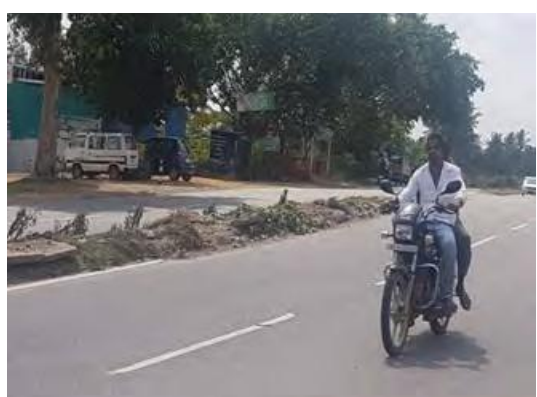

Fig. 13: Damaged median at ch.202.300 Km

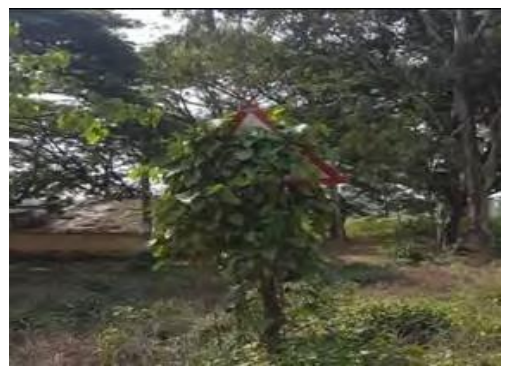

Fig. 14: Sign board covered with vegetation at ch.188.100 Km

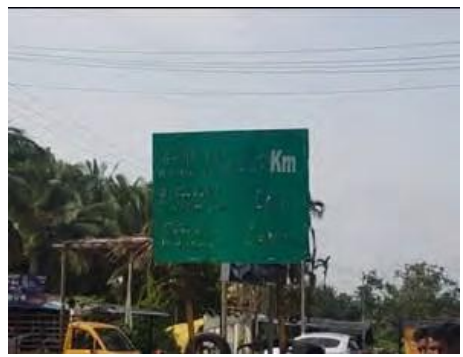

Fig. 15: Poor condition of sign Board at ch.190.100 Km

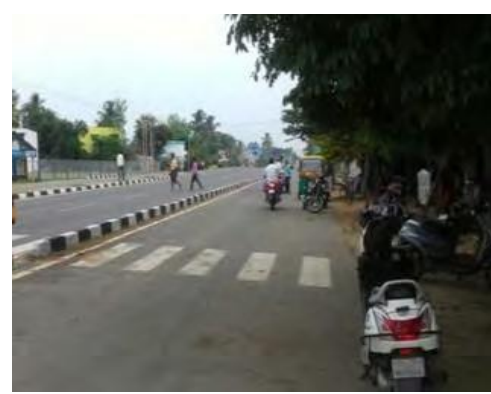

Fig. 16: Poor visibility of Bus stop at ch.197.300 Km

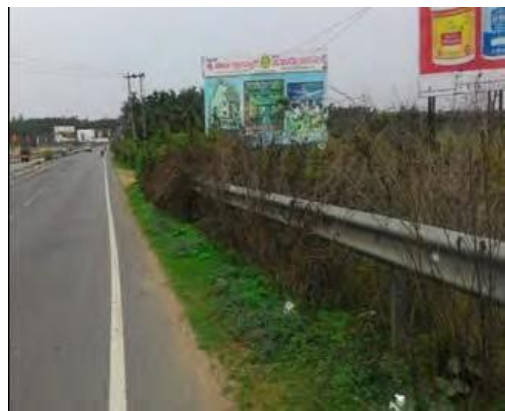

Fig. 17: Vegetation covering over barrier

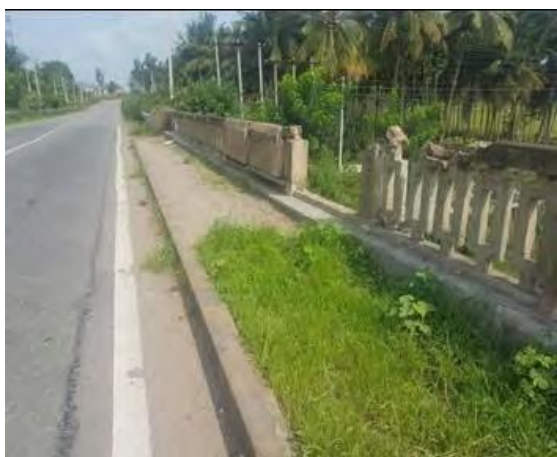

Fig. 18: Damaged parapet

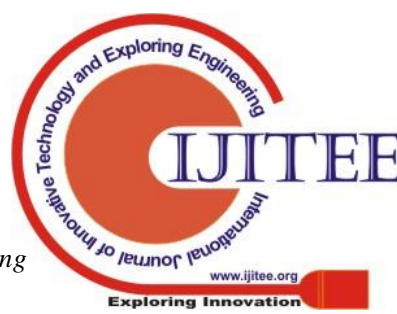




\section{CONCLUSION}

Thepresentworkismadetoconductroadsafetyauditforthe existinghighwayi.e., fromch.183.100-ch.192.500whichis bypasssectionandch.192.500-ch.205.200whichisfourlane highway. Accident data is collected from 3 police stations and it is observed that from 2012-16 accident rates is less varied. Because of recently upgraded four lanes national Highway-69fromkm192.200tokm205.200,thosehighway guidelines have been brought up abruptly. Be that as other relatedfactorswouldnotbringshouldthislevelforexample, roaduserbehavior,encompassingprevailingstatesandsoon.

Manyvillagescomealongtheprojectstretch,sointersections aremoreandalsopedestriantrafficandtwowheelertrafficis more. But safety measures such as sight distance, placement and maintenance of sign boards, marking at these junctions are not good. Throughout the stretch shoulder width is varyinganditiscoveredbyvegetation, soitcausesdrainage problem and bus bays are occupied for parking and some agricultural activities. Crash barriers are not maintained properly, markings on road, divider are averagely maintained.Reflectingpropertiesofsignboardsaredamaged due to irregularmaintenance.

Hence, there is needed to develop the knowledge about the trafficconditions,signboards,roadmarkingsamongtheroad users and regular auditing to improve the road safety is necessarybyhighwayauthorities.

\section{REFERENCES}

1. ArunSBagiandDheerajNkumar"RoadSafetyAudit"IOSRJourn alof Mechanical and Civil Engineering (IOSRJMCE)

2. Atul Kumar, Engineering Design Standards to Ensure Road Safety: Experiences fromIndia.

3. CodeofPracticeforRoadmarking,IRC:351997, IndianRoadCongress, NewDelhi.

4. Code of Practice for Road Signs, IRC:67-2012, Indian Road Congress, NewDelhi.

5. KayithaRavinder and Dr.JakklaNataraju, scientist, CSIR, "Road Safety Audit of National Highways in India at ConstructionStage".

6. Manish.D.Katiyari, "Road Safety Audit: A Case Study for Wardha Road in Nagpur City.

7. Manual for Specifications \& Standards for Four Laning of Highways Through Public Private Partnership, IRC:SP-842009, Indian Road Congress, NewDelhi.

8. ManualofStandards\&SpecificationsforTwoLaningofStateHigh ways on B.O.T. Basis, IRC: SP: 73-2007, Indian Road Congress, NewDelhi.

9. ManualonRoadSafetyAudit,IRC:SP:882010,IndianRoadCongress, NewDelhi.

10. MinistryofRoadTransportandHighways,Ref:no.

11. MinistryofRoadTransportandHighways,Ref:no. RW/NH29011/2/2015/P\&M(RSCE).

12. PavanDeshpande, Review article on " Road Safety and Accident Prevention inIndia".

13. RecommendedPracticeforRoadDelineators,IRC:79198,IndianRoad Congress, NewDelhi.

14. SSJain,P.K.Singh,Dr.MParida(9),"RoadSafetyAuditForFourL ane NationalHighway"

15. Type Designs for Pick-up Bus Stops on Rural (i.e., NonUrban) Highways, IRC: 80-1981, Indian Road Congress, NewDelhi.

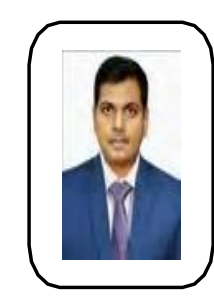

\section{AUTHORS PROFILE}

Dr. Jayaprakash $\mathbf{M}$ C has been completed his Ph.D in Geoinformatics in Mangalore University, Karnataka, He worked in many National level natural resources projects which was sponsored by Indian Space Research Organisation,Govt.ofIndia:AsaScientistat KSRSAC,

Bangalore. Presently, he is working as a associate professor in Dept. of Civil Engineering, MITE, Moodabidri since from 2013. He is a life member of 'The Indian Science Congress Association', from2015 and Secretary, CAFET Innova Technical Society, MITE Chapter.

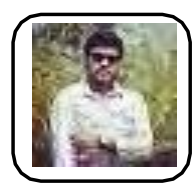

Mr. Shreyas K S has been completed M.Tech in Transportation Engineering at JNNCE Shimoga and 